\title{
Supporting Information \\ For \\ Total Utilization of Miscanthus Biomass, Lignin and Carbohydrates, Using Earth Abundant Nickel Catalyst
}

Hao Luo, Ian M. Klein, Yuan Jiang, Hanyu Zhu, Baoyuan Liu, Hilkka I. Kenttämaa, and Mahdi M. Abu-Omar*

* Email: $\underline{\text { mabuomar@purdue.edu }}$

Summary of Content:

11 Pages

2 Figures

Figure S1 (a)-(b)

Figure S2 (a)-(g)

2 Tables

\section{Instrumentation and Chromatographic Conditions}

\section{HPLC-MS analysis}

All HPLC separations for mass spectrometry analysis were performed on a Surveyor Plus HPLC system from Thermo Scientific consisting of a quaternary pump, an autosampler, a photodiode array (PDA) detector, and a Zorbax SB-C18 column. A non-linear gradient of water (A) and acetonitrile (B) was used as follows: $0.00 \mathrm{~min}$, 95\% $\mathrm{A}$ and $5 \% \mathrm{~B} ; 10.00 \mathrm{~min}, 95 \% \mathrm{~A}$ and $5 \% \mathrm{~B} ; 30.00 \mathrm{~min}, 40 \% \mathrm{~A}$ and $60 \% \mathrm{~B} ; 35.00$ $\min , 5 \% \mathrm{~A}$ and $95 \%$; 38.00min, 5\% $\mathrm{A}$ and $95 \% \mathrm{~B} ; 38.50 \mathrm{~min}, 95 \% \mathrm{~A}$ and $5 \% \mathrm{~B}$; $45.00 \mathrm{~min}, 95 \% \mathrm{~A}$ and $5 \% \mathrm{~B}$. Flowrate of the mobile phase was kept at $500 \mu \mathrm{L} / \mathrm{min}$. PDA detector was set at the wavelength of $254 \mathrm{~nm}$.

Mass spectrometric analysis (MS, $\mathrm{MS}^{2}$ and $\mathrm{MS}^{3}$ ) of HPLC eluent was performed using a Thermo Scientific linear quadrupole ion trap (LQIT) mass spectrometer equipped with an electrospray ionization (ESI) source. All mass spectrometry experiments were performed under negative ion mode. HPLC eluents were mixed via a T-connector with $1 \%$ sodium hydroxide water solution at a flow rate of $0.1 \mu \mathrm{L} / \mathrm{min}$ before entering the ESI source. Addition of sodium hydroxide facilitates deprotonation of the analytes. ESI source conditions were set as: $3.5 \mathrm{kV}$ spray voltage; 50 (arbitrary units) sheath gas $\left(\mathrm{N}_{2}\right)$ flow and 20 (arbitrary units) auxillary gas $\left(\mathrm{N}_{2}\right)$ flow.

$\mathrm{MS}^{3}$ analysis was performed using the data dependent scan function of the Thermo Xcalibur software. The most abundant ion formed upon ESI was isolated and subjected to collision-activated dissociation (CAD). The most abundant fragment ion was further selected for isolation and fragmentation. For all $\mathrm{MS}^{3}$ experiments, an 
isolation window of $2 \mathrm{~m} / \mathrm{z}$ units was used along with a normalized collision energy of 30 (arbitrary units). All mass spectrometry experiments were performed under negative ion mode.

\section{HPLC/GC analysis}

The liquid phase from lignin depolymerization reactions with methanol as solvent was analyzed with Agilent 1260 Infinity Quaternary High-Performance Liquid Chromatography (HPLC) system, using Zorbax Eclipse XDB-C18 Column (250 x $74.6 \mathrm{~mm}$ ) set at $30^{\circ} \mathrm{C}$. The chromatography apparatus is equipped with G1315D Diode Array Detector (DAD). A mixture of $\mathrm{H}_{2} \mathrm{O}(\mathrm{A})$ and acetonitrile (B) were used as the mobile phase at a flow rate of $0.5 \mathrm{~mL} / \mathrm{min}$. Nonlinear gradient was used $(80 \% \mathrm{~A}$ and $20 \% \mathrm{~B}$ from beginning to $5 \% \mathrm{~A}$ and $95 \% \mathrm{~B}$ at $55.0 \mathrm{~min})$. A fixed amount (400 $\mu \mathrm{L})$ of internal standard 3-methoxy phenol $(10 \mathrm{mM})$ was added into each sample for the quantification purposes. Standard curves for all the aromatic products were made by comparison of the products to internal standard. All results were analyzed and quantified according to standard curves. Before analyzing by HPLC, the liquid samples were filtered through a $0.22 \mu \mathrm{m}$ cutoff syringe filter ( $25 \mathrm{~mm}$ diameter).

All sugar samples as well as aqueous phase after solid carbohydrate dehydration reaction were analyzed with Agilent 1260 Infinity Quaternary High-Performance Liquid Chromatography (HPLC) system, using Aminex HPX-87H column (300 x 7.8 $\mathrm{mm}$ ) set at $70{ }^{\circ} \mathrm{C}$. The chromatography apparatus is equipped with G1362A Refractive Index Detector (RID) calibrated with external standards. A $0.005 \mathrm{M}$ sulfuric acid solution was employed as the mobile phase with flow of $0.6 \mathrm{~mL} / \mathrm{min}$. A fixed amount $(400 \mu \mathrm{L})$ of internal standard tert-butyl alcohol $(10 \mathrm{mM})$ was added into each sample for quantification purposes. Standard curves (glucose, xylose, and arabinose) were made by comparison of the products with internal standard. All results were analyzed and quantified according to standard curves. Before analyzing by HPLC, the aqueous solutions were filtered through a $0.22 \mu \mathrm{m}$ cutoff syringe filter ( $25 \mathrm{~mm}$ diameter).

The organic phase after solid carbohydrate dehydration reaction was analyzed by Agilent Technologies 6890N Network Gas Chromatography (GC) System, equipped with a J\&W Scientific DB-5 capillary column. Oven temperature was ramped from 50 ${ }^{\circ} \mathrm{C}$ to $250{ }^{\circ} \mathrm{C}$ at $15{ }^{\circ} \mathrm{C} \min ^{-1}$, and from $250{ }^{\circ} \mathrm{C}$ to $300{ }^{\circ} \mathrm{C}$ at $25{ }^{\circ} \mathrm{C} \mathrm{min}{ }^{-1}$ by using constant flow mode at $1.0 \mathrm{~mL} \mathrm{~min}^{-1}$. Products (furfural and levulinic acid) were identified by retention time and compared to standards. Products were quantified by using a standard calibration curve. Before analyzing by GC, the organic solutions were filtered through a $0.22 \mu \mathrm{m}$ cutoff syringe filter $(25 \mathrm{~mm}$ diameter $)$. 
Figure S1. Aromatic products after lignin depolymerizatoin reaction.

(a)

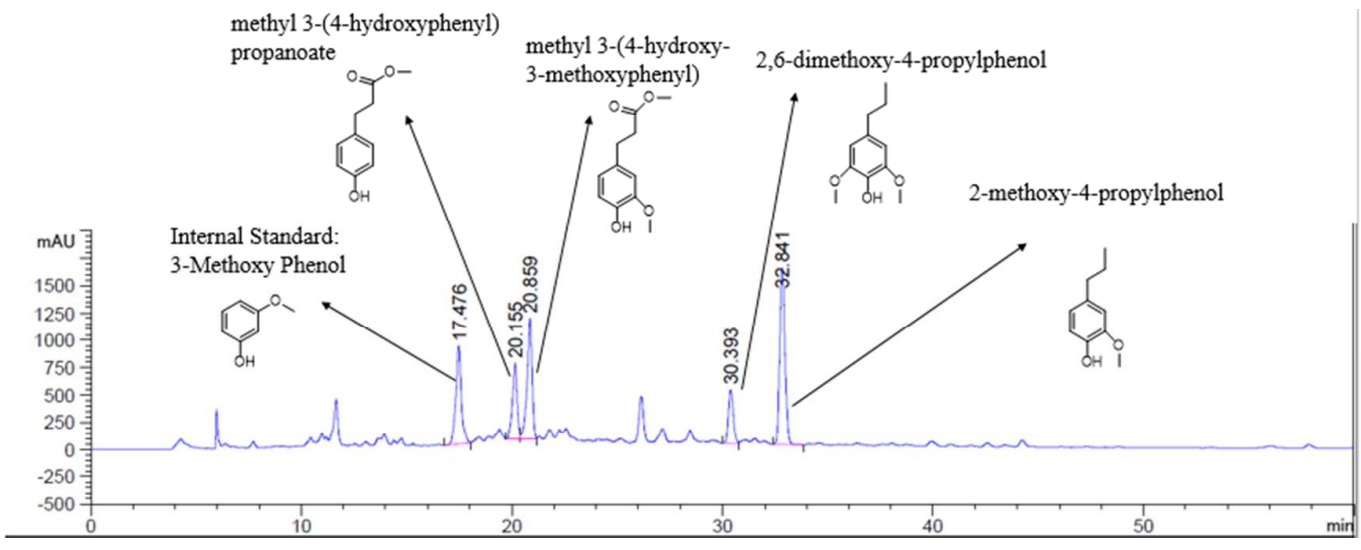

(b)

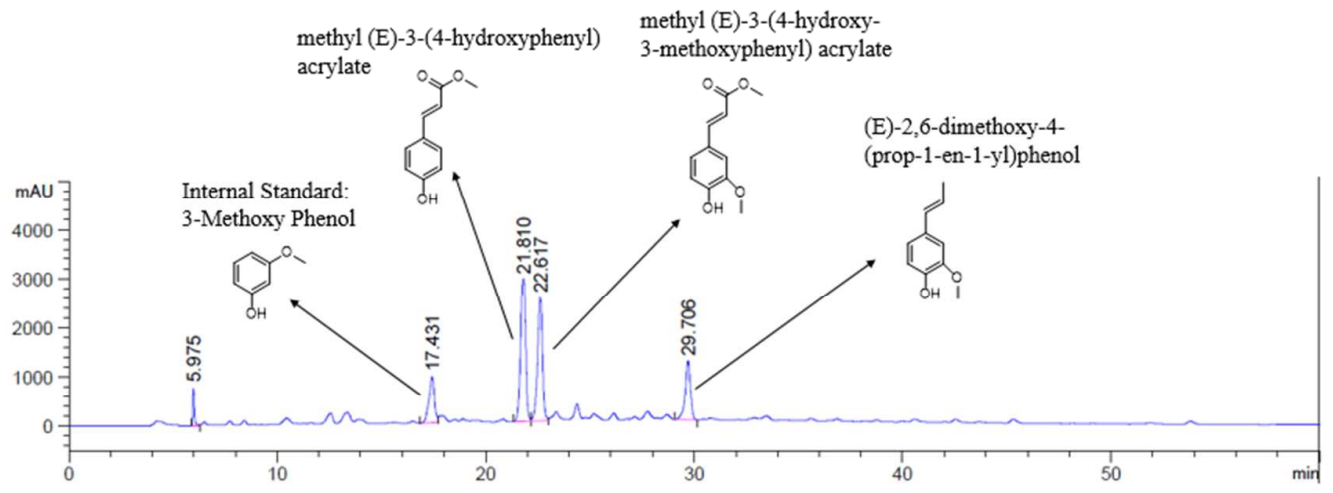

(a). HPLC/UV for single bond branch chain aromatic products from lignin depolymerization.

(b). HPLC/UV for double bond branch chain aromatic products from lignin depolymerization. 
Figure S2. ESI(-)//MS ${ }^{\mathrm{n}}$ analysis of standard compounds and aromatic products derived from catalytic lignin depolymerization reactions.

(a) CAD spectrum of pure 2-methoxy-4-propylphenol as well as $\mathrm{m} / \mathrm{z}=165$ in lignin depolymerzation products.

CAD spectrum of 2-methoxy-4-propylphenol $(\mathrm{m} / \mathrm{z}=165)$
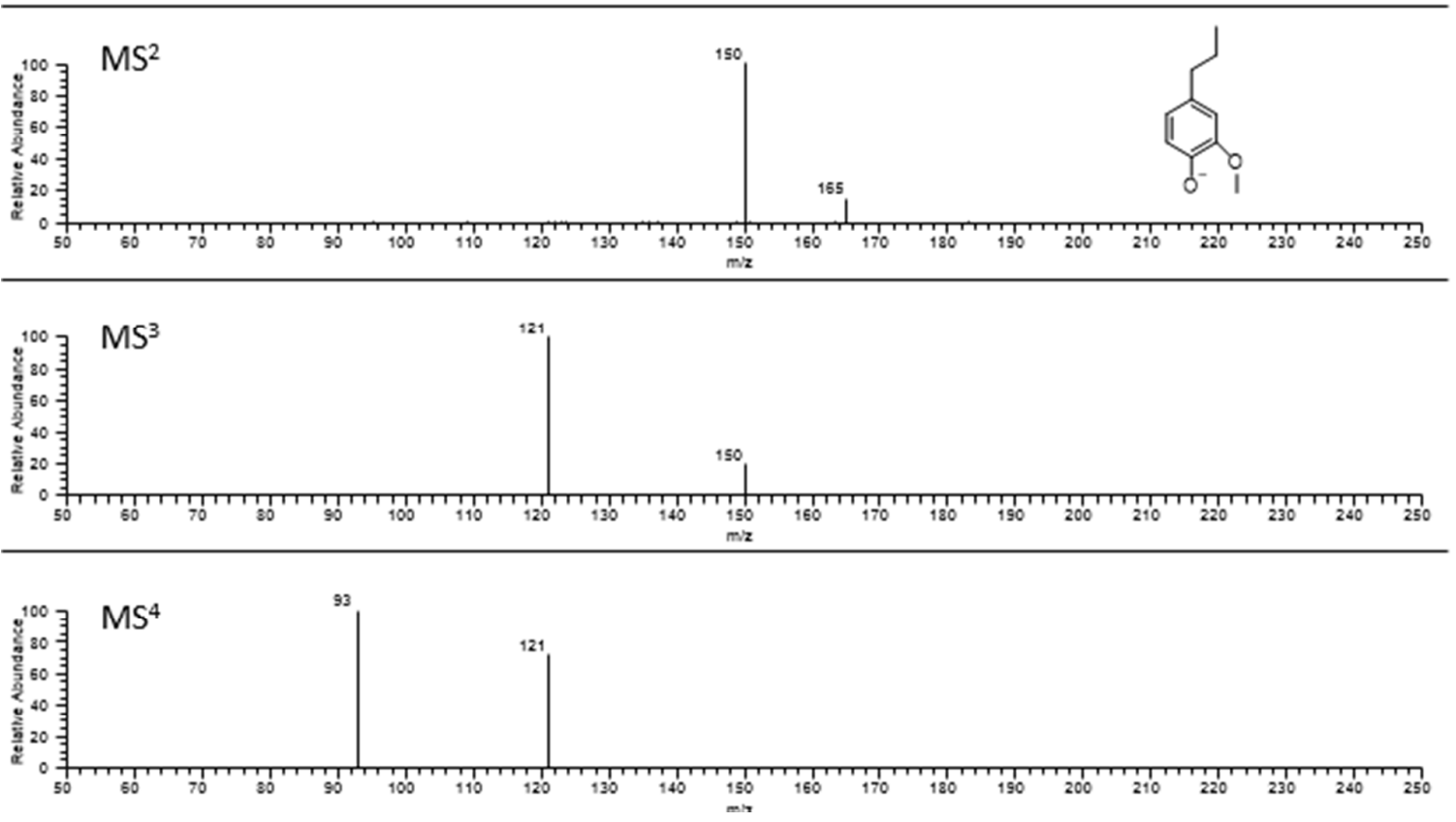


\section{CAD spectrum of ion $\mathrm{m} / \mathrm{z}=165$ in lignin depolymerization products}
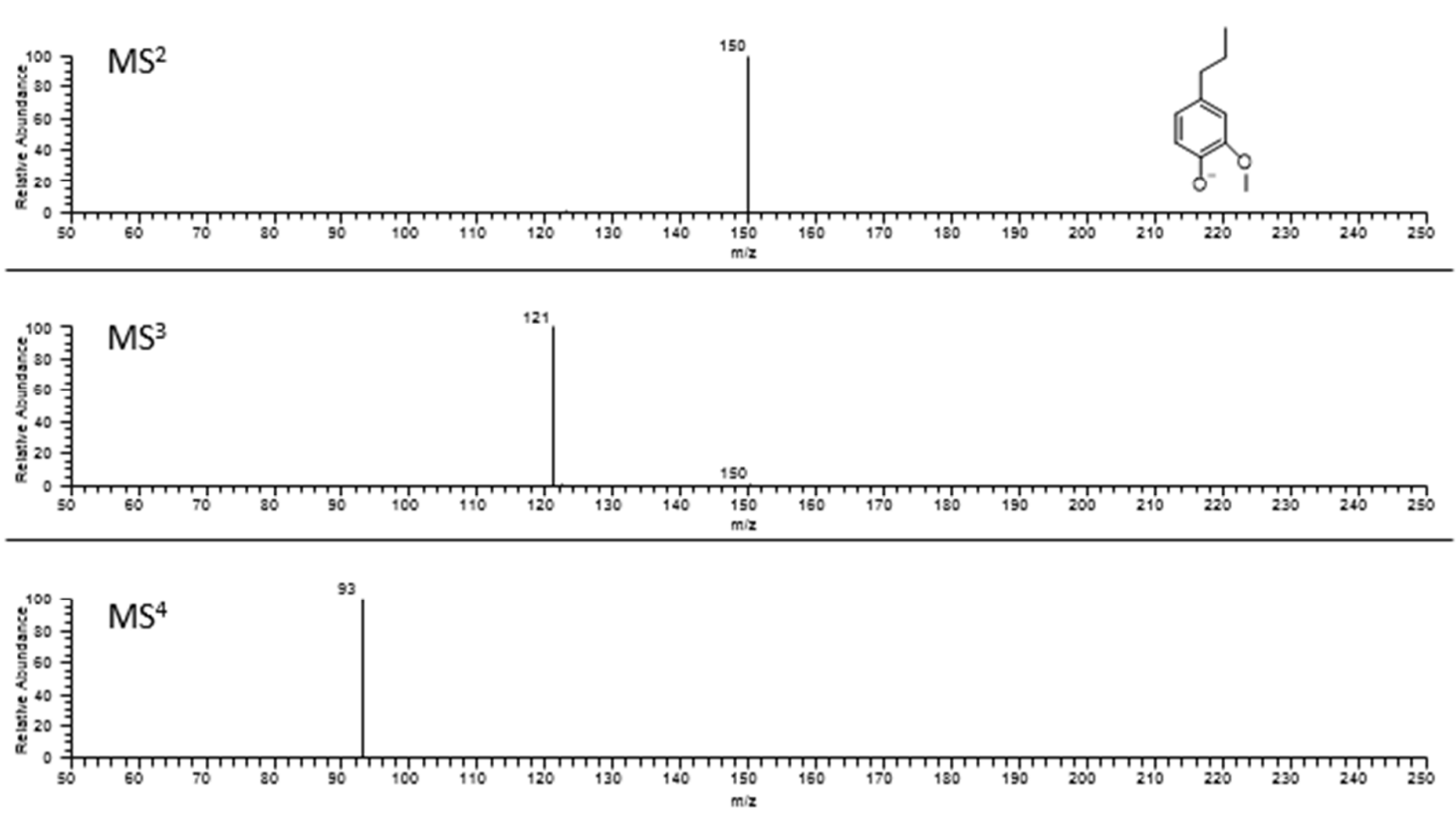

(b) CAD spectrum of pure 2,6-dimethoxy-4-propylphenol as well as $\mathrm{m} / \mathrm{z}=195$ in lignin depolymerzation products.

\section{CAD spectrum of 2,6-dimethoxy-4-propylphenol $(\mathrm{m} / \mathrm{z}=195)$}
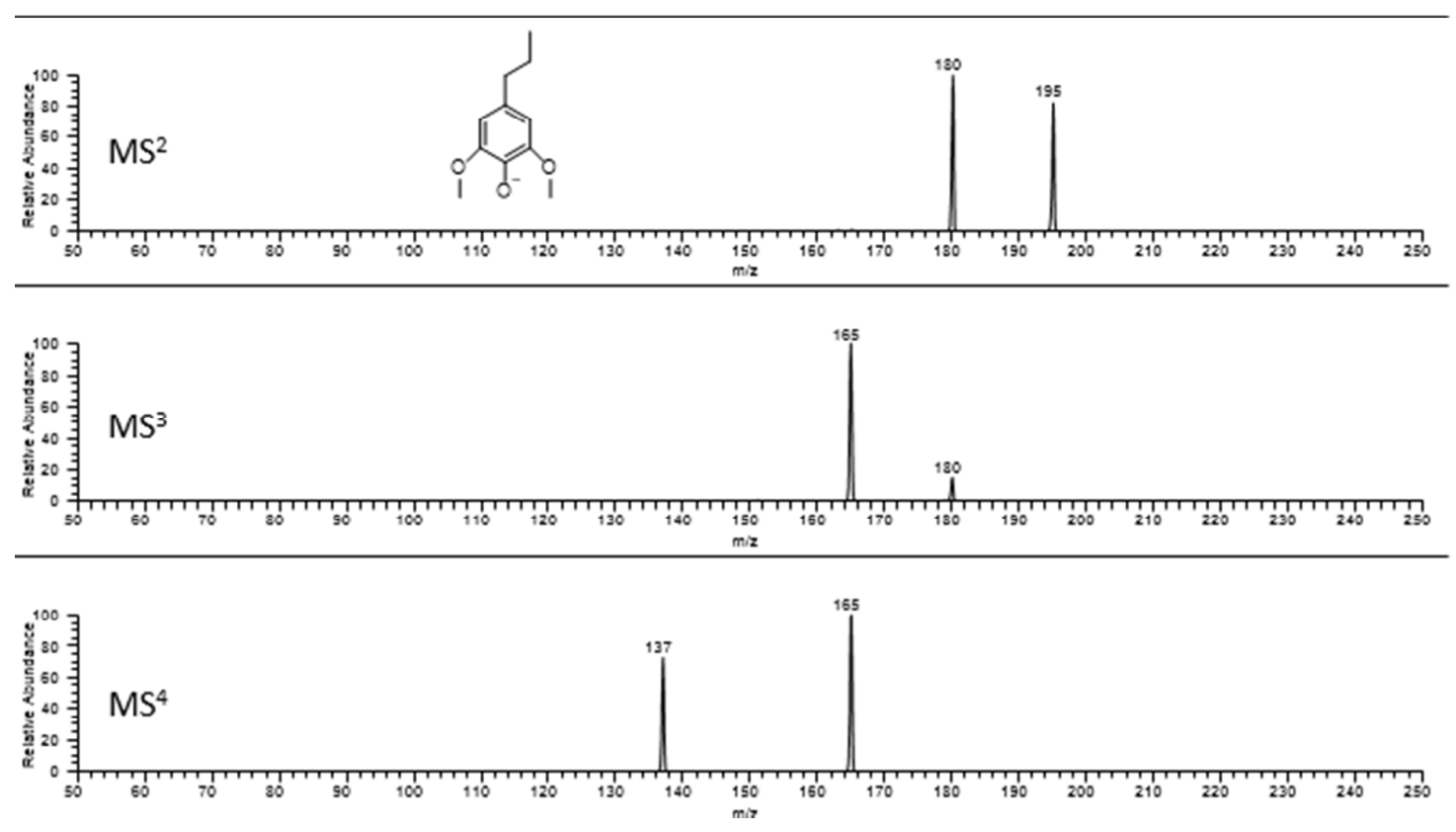


\section{CAD spectrum of $\mathrm{m} / \mathrm{z}=195$ in lignin depolymerization products}
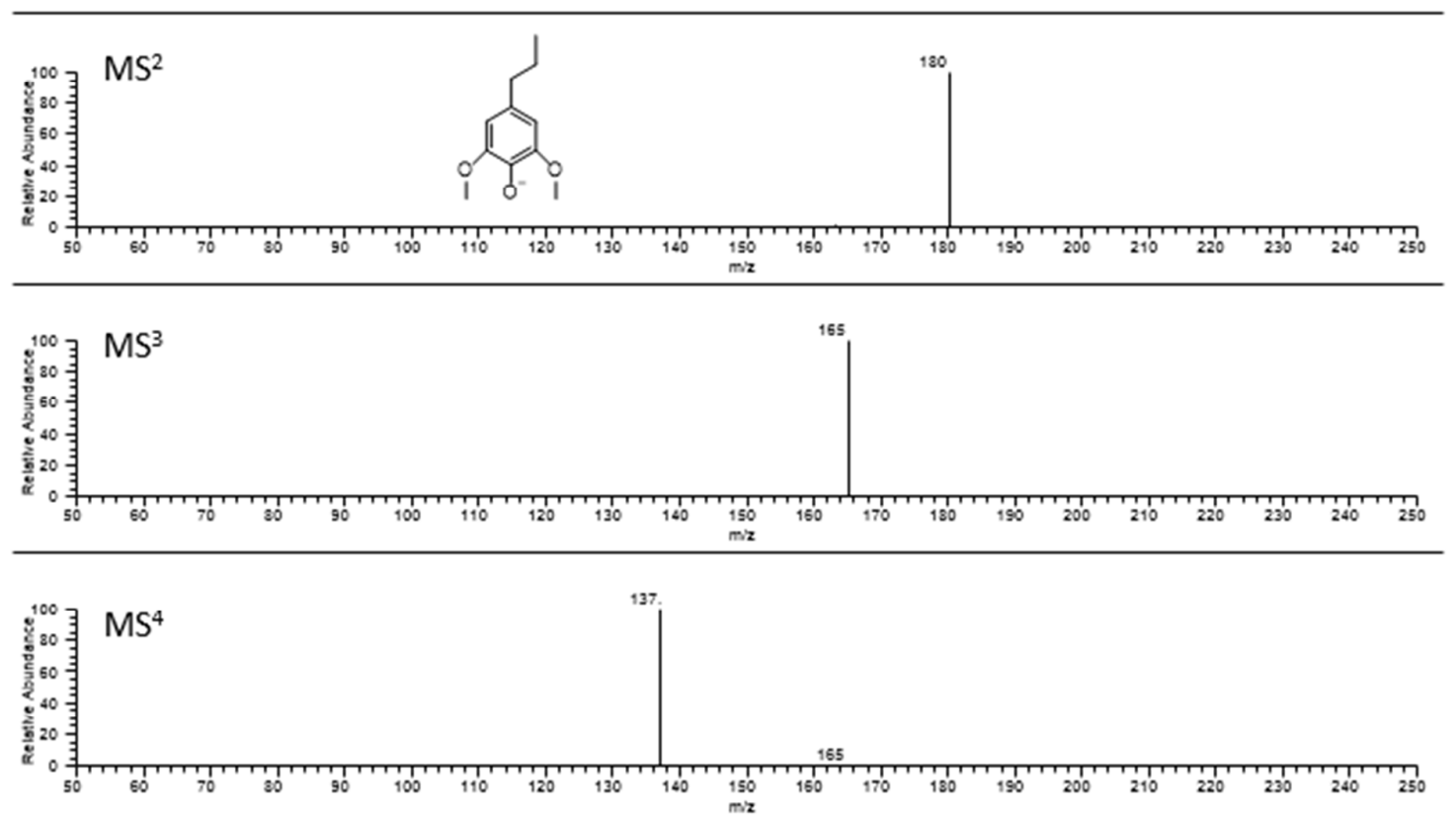

(c) CAD spectrum of pure methyl 3-(4-hydroxyphenyl) propanoate as well as $\mathrm{m} / \mathrm{z}=$ 179 in lignin depolymerzation products.

CAD spectrum of methyl 3-(4-hydroxyphenyl) propanoate $(\mathrm{m} / \mathrm{z}=179)$
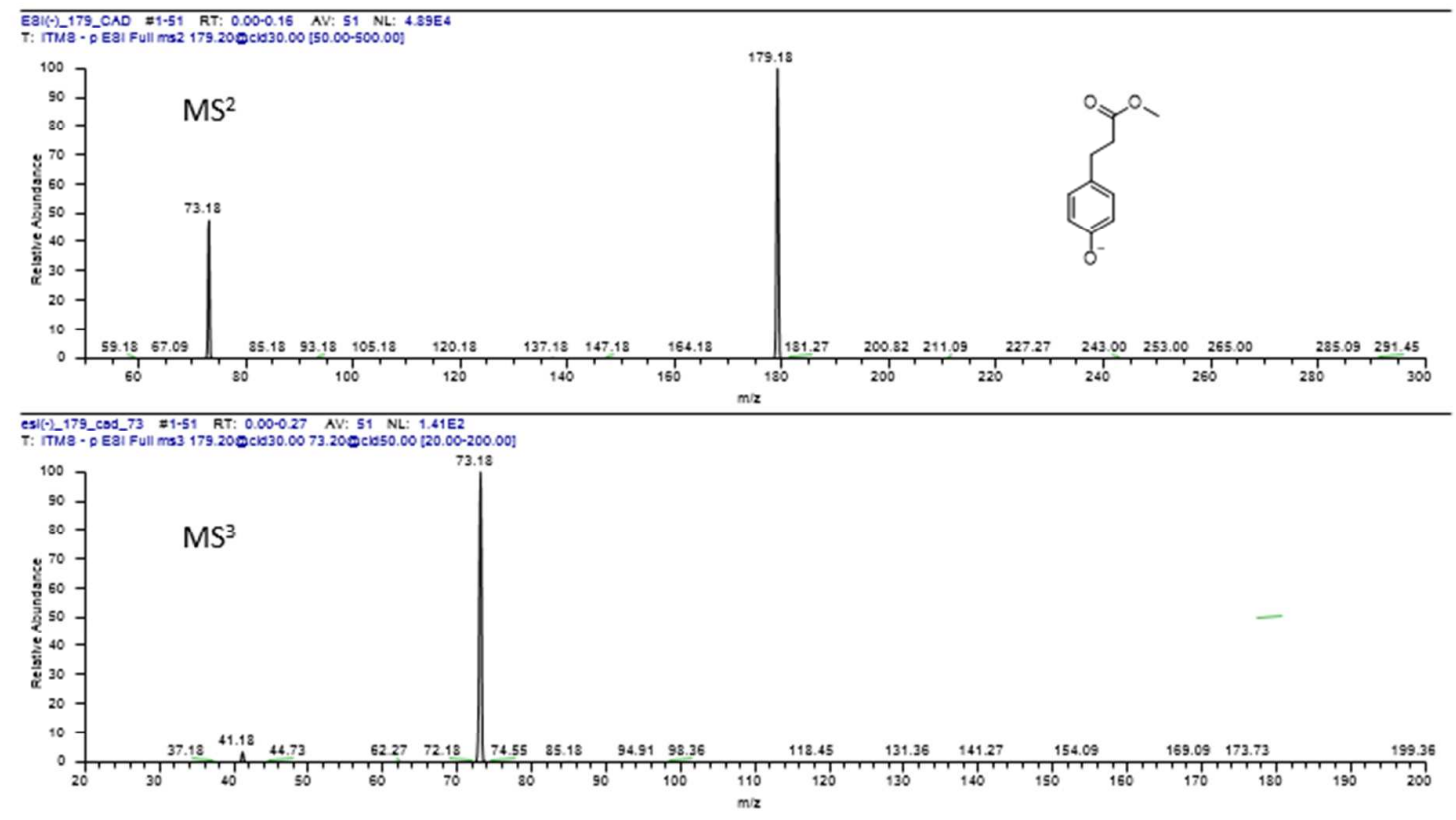


\section{CAD spectrum of $\mathrm{m} / \mathrm{z}=179$ in lignin depolymerization products}
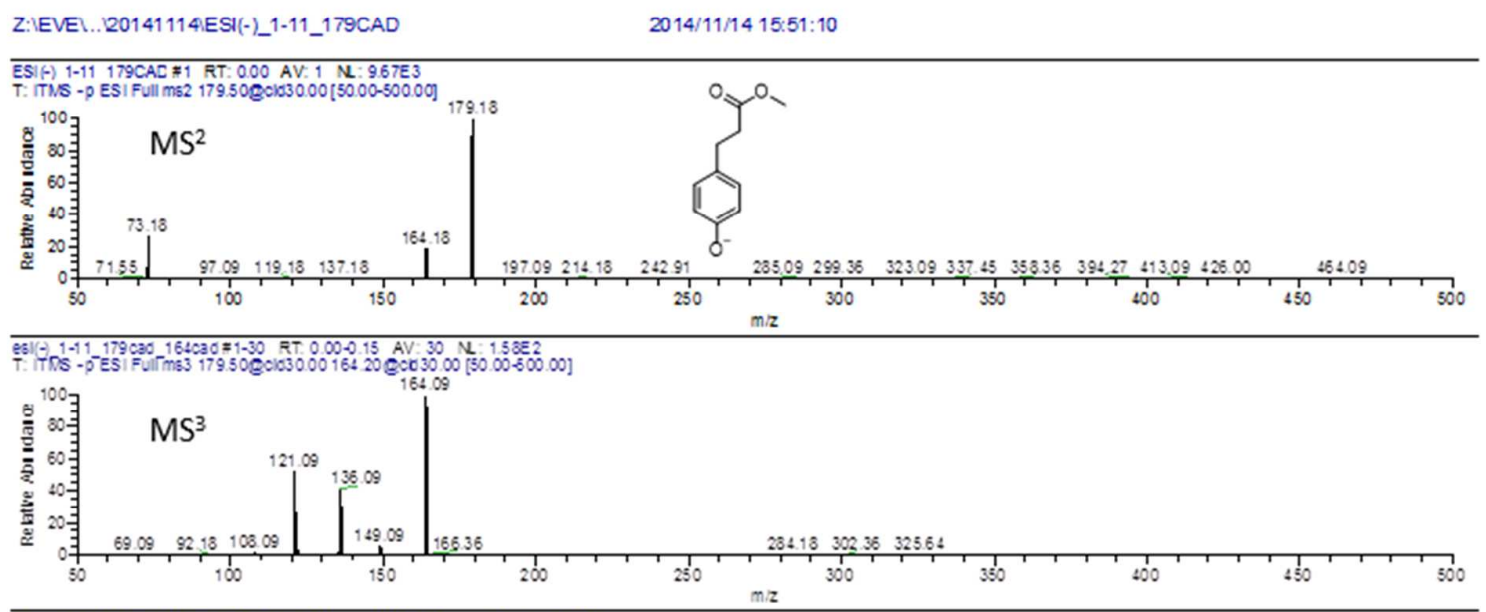

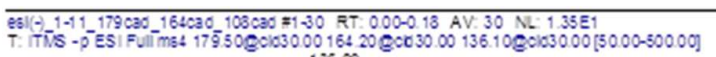

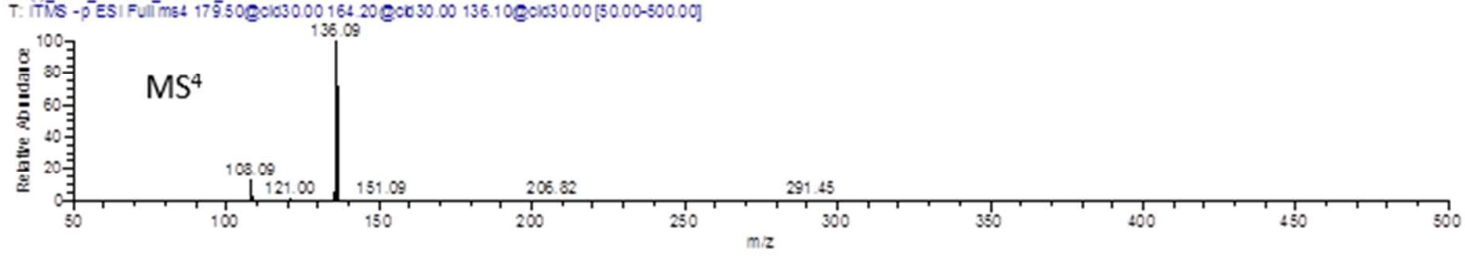

(d) CAD spectrum of pure methyl 3-(4-hydroxy-3-methoxyphenyl) as well as $\mathrm{m} / \mathrm{z}=$ 209 in lignin depolymerzation products.

\section{CAD spectrum of methyl 3-(4-hydroxy-3-methoxyphenyl) $(\mathrm{m} / \mathrm{z}=209)$}

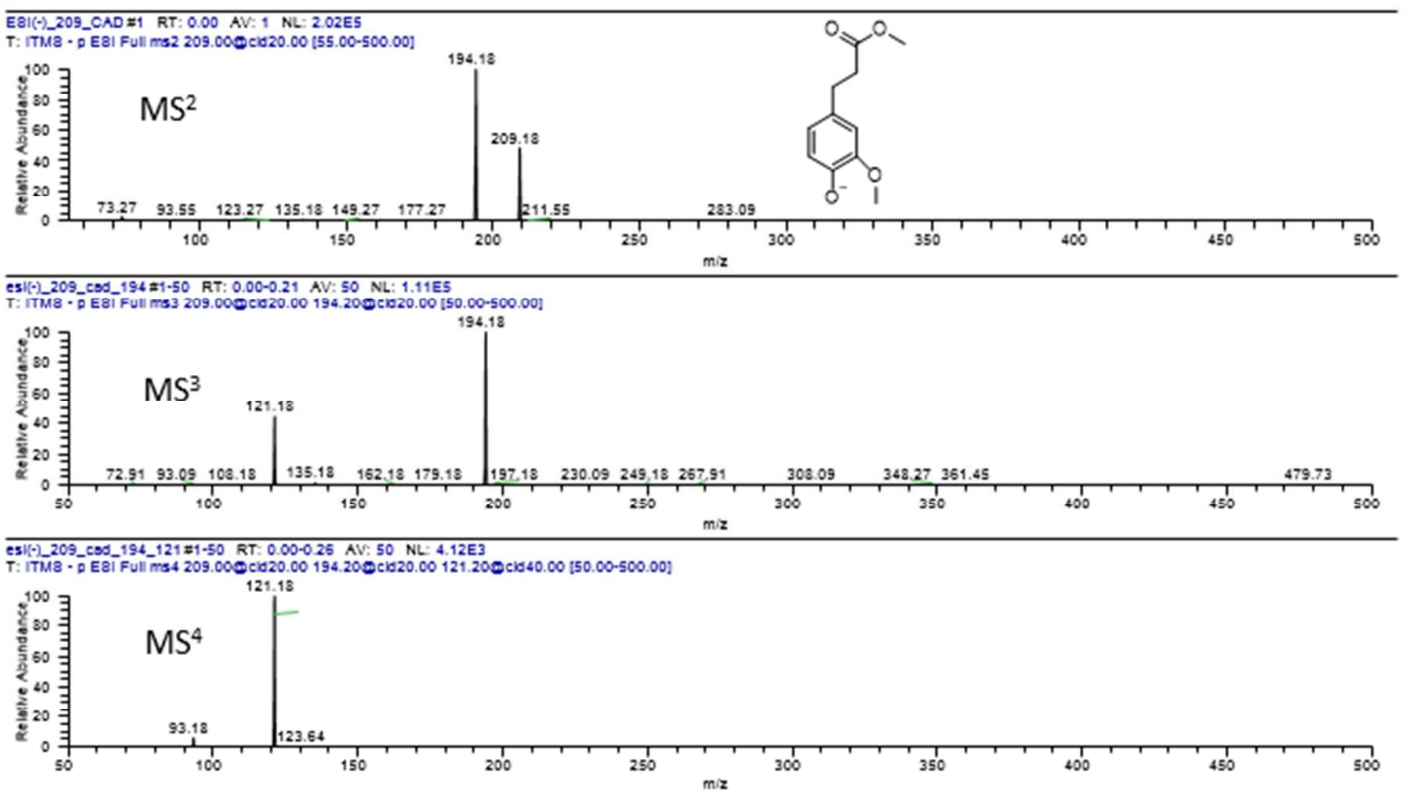




\section{CAD spectrum of $\mathbf{m} / \mathbf{z}=\mathbf{2 0 9}$ in lignin depolymerization products}
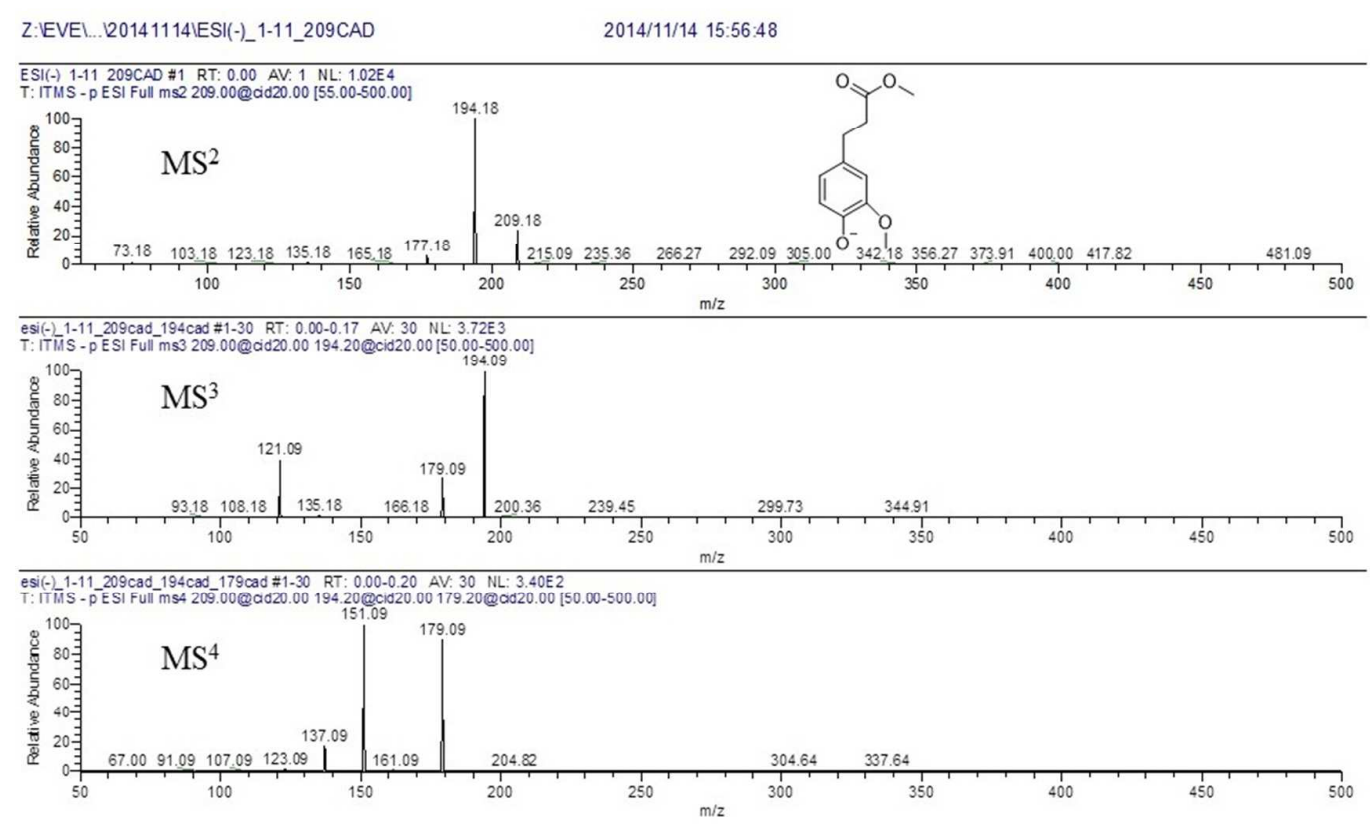

(e) CAD spectrum of pure isoeugenol as well as $\mathrm{m} / \mathrm{z}=163$ in lignin depolymerzation products.

\section{CAD spectrum of isoeugenol $(\mathrm{m} / \mathrm{z}=163)$}
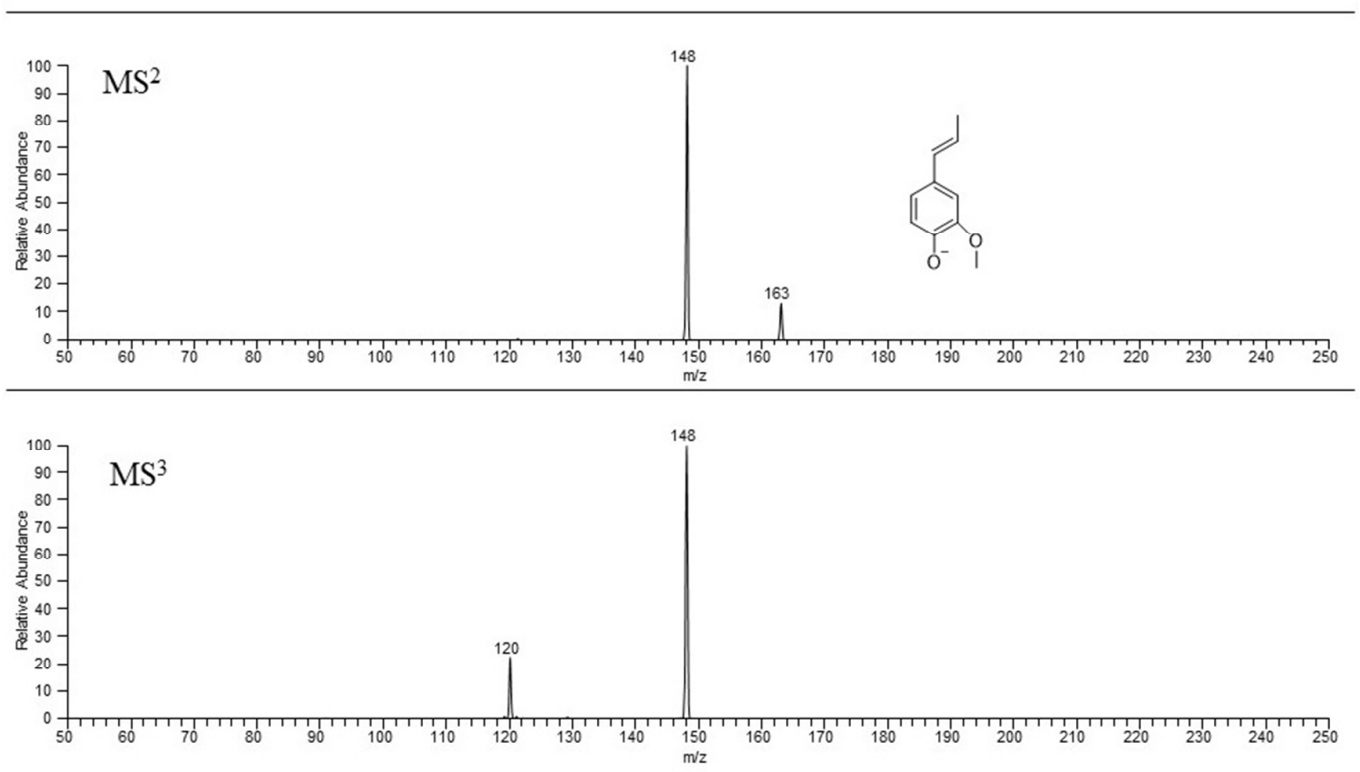


\section{CAD spectrum of ion $\mathrm{m} / \mathrm{z}=163$ in lignin depolymerization products}
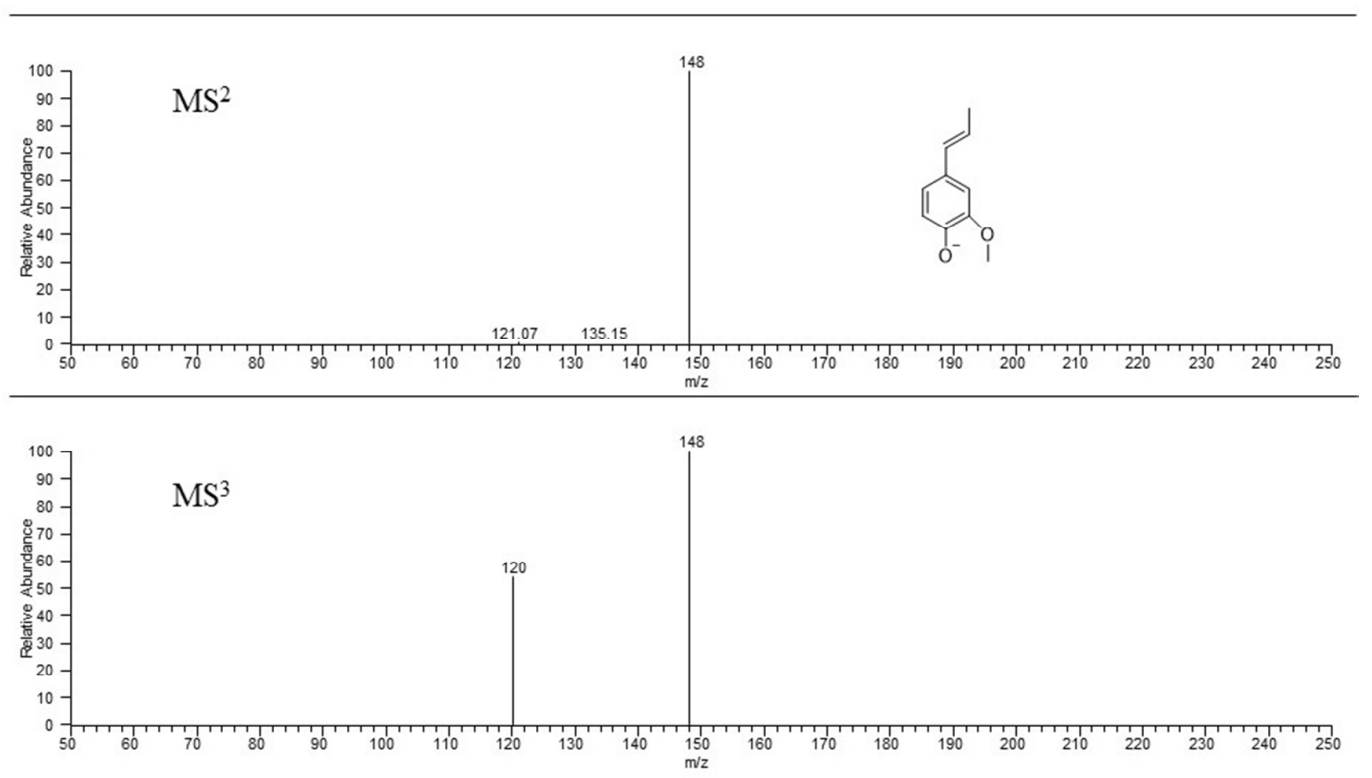

(f) CAD spectrum of pure methyl (E)-3-(4-hydroxyphenyl) acrylate as well as $\mathrm{m} / \mathrm{z}=$ 177 in lignin depolymerzation products.

\section{CAD comparison of methyl 3-(4-hydroxy-3-methoxyphenyl) and lignin depolymerization} product at $\mathrm{m} / \mathrm{z}=\mathbf{1 7 7}$
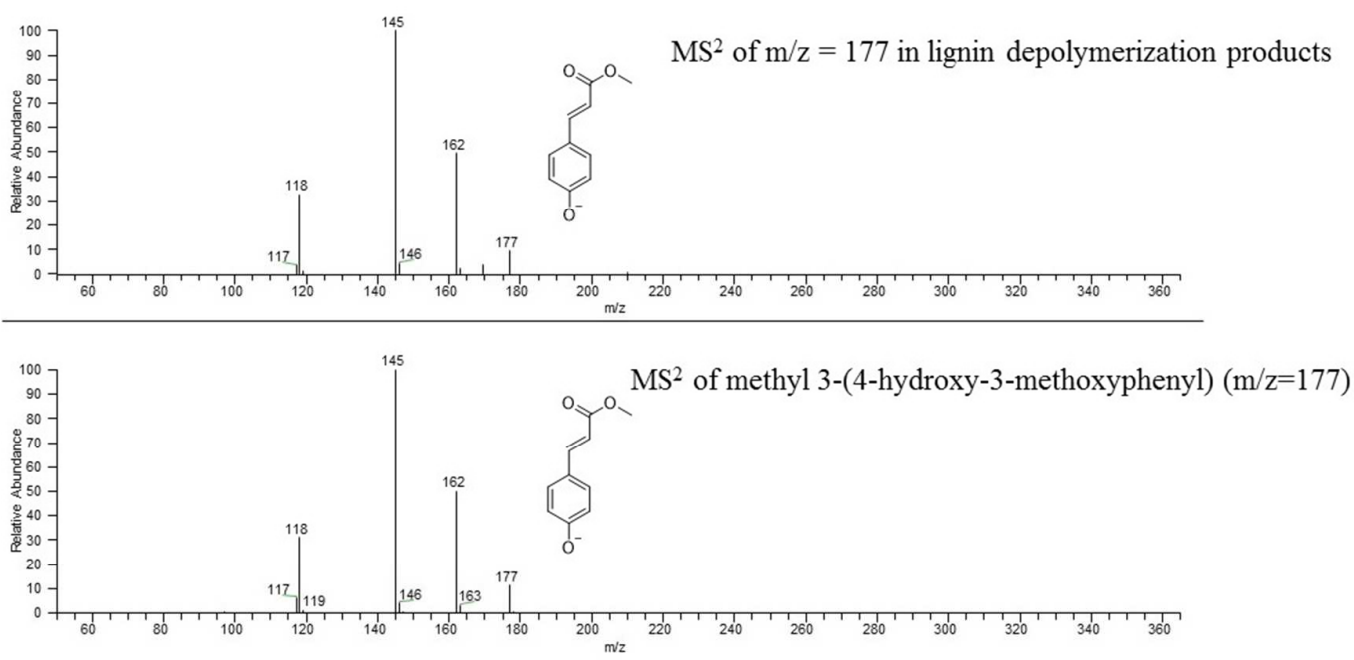
(g) CAD spectrum of pure methyl (E)-3-(4-hydroxy-3-methoxyphenyl) acrylate as well as $\mathrm{m} / \mathrm{z}=207$ in lignin depolymerzation products.

CAD comparison of methyl (E)-3-(4-hydroxy-3-methoxyphenyl) acrylate and lignin depolymerization product at $\mathbf{m} / \mathrm{z}=\mathbf{2 0 7}$
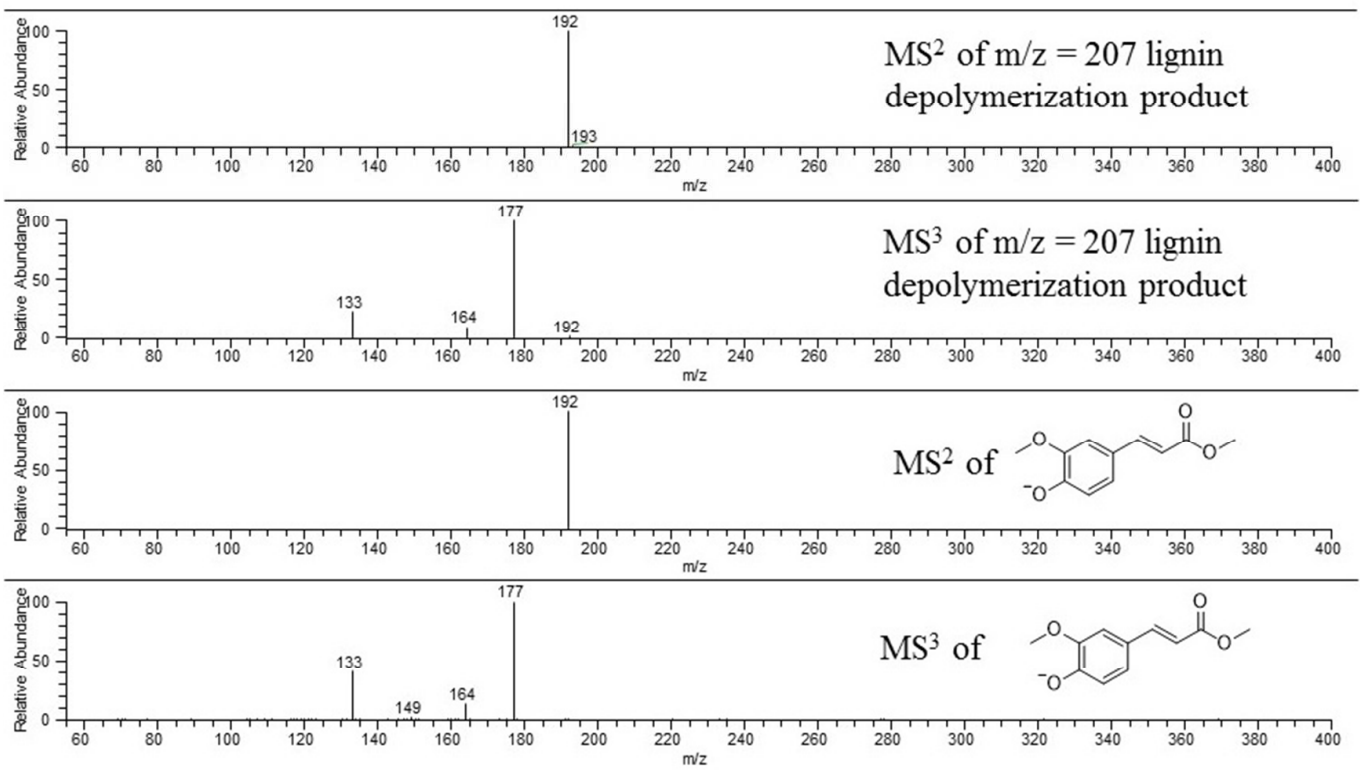

\section{Carbohydrate determination in methanol phase}

In order to determine the sugar content in the methanol phase after LDP reaction, 20 $\mathrm{mL}_{2} \mathrm{O}$ was first added into $10 \mathrm{~mL}$ methanol solution. The resulting solution was then extracted with $20 \mathrm{~mL}$ diethyl ether three times to remove aromatic products. The methanol- $\mathrm{H}_{2} \mathrm{O}$ layer was collected, and methanol was removed from $\mathrm{H}_{2} \mathrm{O}$ under reduced pressure. The $\mathrm{H}_{2} \mathrm{O}$ layer which contains carbohydrate was subjected to acid hydrolysis by following standard NREL procedures, and the solution was analyzed by HPLC. ${ }^{[1]}$

Table S1. Sugar content in methanol phase after lignin depolymerization (LDP) reaction

Entry Carbohydrates in liquid phase

LDP Reaction Conditions

\begin{tabular}{llllll} 
& Glucan $(\mathrm{mg})$ & Xylan $(\mathrm{mg})$ & Arabinan $(\mathrm{mg})$ & Total $(\mathrm{mg})$ & \\
\hline $\mathbf{1}$ & 1 & 9 & 6 & 16 & $15 \mathrm{wt} \% \mathrm{Ni} / \mathrm{C}$ in cage, $35 \mathrm{bar} \mathrm{H}_{2}$ \\
\hline $\mathbf{2}$ & 2 & 11 & 7 & 20 & $10 \mathrm{wt} \% \mathrm{Ni} / \mathrm{C}$ in cage, 35 bar $\mathrm{H}_{2}$
\end{tabular}




\begin{tabular}{llllll}
\hline $\mathbf{3}$ & 2 & 13 & 6 & 21 & $10 \mathrm{wt} \% \mathrm{Ni} / \mathrm{C}$ in cage, $10 \mathrm{bar} \mathrm{H}_{2}$ \\
\hline $\mathbf{4}$ & 2 & 12 & 6 & 20 & $10 \mathrm{wt} \% \mathrm{Ni} / \mathrm{C}$ in cage, $35 \mathrm{bar} \mathrm{N}_{2}$ \\
\hline $\mathbf{5}$ & 1 & 9 & 8 & 18 & No catalyst, 35bar $\mathrm{H}_{2}$ \\
\hline $\mathbf{6}$ & 2 & 11 & 6 & 19 & No catalyst, 35bar $\mathrm{N}_{2}$ \\
\hline
\end{tabular}

Mass balance calculation

Table S2. Reaction mass balance calculation after catalytic LDP reaction by using $\mathrm{Ni} / \mathrm{C}$ as catalyst. ${ }^{\mathrm{a}}$

\begin{tabular}{|c|c|c|c|c|c|c|c|}
\hline \multirow{4}{*}{$\underset{b}{\text { Entry }}$} & \multicolumn{3}{|c|}{ Liquid Phase \% } & \multicolumn{3}{|c|}{ Solid Phase\% } & \multirow[t]{4}{*}{ Total\% } \\
\hline & Ether & Water & Others $\%$ & Sugars $\%$ & Ash $\%$ & Others $\%$ & \\
\hline & Soluble & Soluble & & & & & \\
\hline & Aromatics $\%$ & Sugars $\%$ & & & & & \\
\hline 1 & 9 & 2 & 20 & 57 & 2 & 8 & 98 \\
\hline 2 & 8 & 2 & 14 & 57 & 1 & 9 & 91 \\
\hline 3 & 4 & 2 & 20 & 56 & 1 & 11 & 94 \\
\hline 4 & 3 & 2 & 18 & 55 & 1 & 12 & 91 \\
\hline 5 & 3 & 2 & 23 & 56 & 1 & 11 & 96 \\
\hline 6 & 3 & 2 & 21 & 47 & 2 & 22 & 97 \\
\hline
\end{tabular}

a All calculations are based on weight percent $\mathrm{wt} \%$ with regard to miscanthus substrate used for the reactions.

${ }^{\mathrm{b}}$ LDP reaction conditions of Entries 1-6 are in accordance with Entries 1-6 of Table. 4

\section{Ash and others analysis}

Composition analysis of ash in the acid insoluble solid was performed by following standard NERL procedure. ${ }^{[2]}$

\section{References for Supplementary Material:}

[1]. A. Sluiter, B. Hames, R. Ruiz, C. Scarlata, J. Sluiter and D. Templeton, Determination of sugars, byproducts, and degradation products in liquid fraction process samples: Issue Date, 12/08/2006, National Renewable Energy Laboratory, 2006

[2]. A. Sluiter, B. Hames, R. Ruiz, C. Scarlata, J. Sluiter, and D. Templeton, Determination of Ash in Biomass: Issue Date, 07/17/2005, National Renewable 
Energy Laboratory, 2008. 